\title{
Toward a General Mathematical Theory of Behavior
}

\author{
Edward W. Barankin \\ University of California, Berkeley
}

\begin{abstract}
This author has been engaged over the past several years in the effort to develop certain basic intuitions into a fully mathematical theory. These evolving intuitions first began with the idea that the economist's notion of utility might more truly be represented mathematically by a normed measure on the commodity space rather than by a point function, the value of the measure on a particular set of goods having the sense of a relative propensity of the individual to select a good in that set. With this idea there came in turn, quite naturally, the insight that utility and probability are one and the same thing. And accordingly it emerged that the theory we were seeking would not be restricted to the economic behavior of human beings, nor even to the behavior in general of human beings: it would pertain, in utmost generality, to all behavior of all systems. Thus, it must affirm that all behavior is the evolution of stochastic processes, and that all systems are stochastic processes. Consistent with this the structural elements of stochastic processes are seen as the fundamental, objective, real entities, the ultimate buildingblocks of reality. These are eventualities and acts and-according to the traditional mathematical representation of stochastic processes, also-probabilities. This structural aspect of the theory under development puts into sharp evidence its wide divergence from the classical scientific conception of reality.

Our intensive search failed to discover a dynamical law for the proposed new theory within the mathematical context of the traditional, $\sigma$-field-real-valuedmeasure representation of stochastic processes. We therefore have gone on to a higher level of possible mathematical representation. This particular representation would have collections of eventualities represented by lattices of certain configurations in a unitary space. Closed linear manifolds are among these configurations, and indeed the formalism of quantum mechanics falls into the context of this representation. But the general lattice element in the kinds of lattices being investigated is more complicated than a linear manifold, being heuristically comparable with an acute-angle cone of vectors. These configurations are formulated by means of a flanking relation hetween linear manifolds. One such lattice has been developed. Others are currently being sought through variations on the notion of flanking.
\end{abstract}


The fact that probabilities present themselves in the unitary space representation-as is familiar from quantum mechanics-as parameters of the relationship between linear manifolds suggests that probability is not a fundamental structural concept. It is consequently indicated that eventualities and acts alone are the basic elements of real structure. Accordingly, the dynamical law must be formulable in terms of these elements only. There is a natural suggestion of what the law might look like.

Even at the present early stage of development of the new theory being sought it is possible to cite many pieces of empirical evidence vouching for its exclusive validity. Such evidence is particularly noteworthy in the domain of human behavior.

\section{Preface}

On July 1st, 1968, at the invitation of the János Bolyai Mathematical Society, I lectured at the Mathematical Institute of the Hungarian Academy of Science in Budapest ${ }^{1}$, where I endeavored to present a fairly complete outline of my thinking in recent years toward a general mathematical theory of behavior. In that lecture I brought the account of developments entirely up to date for the first time since my talk in Kyoto in May, 1963 (see [6]). That is to say, I included mention of both (1) the program I have been conducting since 1964 for increasing communciation between the predominantly Negro colleges and universities in the United States and other educational institutions, and (2) my recent mathematical work, items [8] - [11] incl., in the References at the end of this article, which may hopefully lead the way to the mathematical foundationing of the intuitions I have been putting forward. I had reported on these two new developments separately on two different occasions in the recent past: in a talk in November, 1967, before the Department of Behavioral Science in the College of Medicine of the University of Kentucky, in Lexington, I described the implications of my theoretical ideas for such a program as this one with the Negro colleges; and in January-February of 1968 I gave two lectures at the Atlanta University Center Science Research Institute where I conveyed some of the results in [8]-[11]. But the Budapest lecture was the first to incorporate both of these topics into a single integrated elaboration of my ideas on behavior.

The present article records the substance of my talk in Budapest. But it also goes well beyond that in content and detail. More than a year has been taken in the writing of the article, and this generous stretch of time has provided two particular advantages. First, it enabled me to develop more fully the mathematical justifications for recent turns in my thinking. And second, it gave me the

1) Sponsors of this visit to Budapest were, in addition to the Jânos Bolyai Mathematical Society, the University of California at Berkeley and the National Science Foundation. 
opportunity to delve much further into certain conceptual questions. During this period, in May, 1969, I was invited to present my ideas at the RAND Corporation in Santa Monica. The astute questioning by the audiences in both Budapest and Santa Monica made it imperative to accomplish the deepening of certain explanations. These more penetrating clarifications are now included here, and I am hopeful that they will both satisfactorily respond to perceptive questioners and successfully demonstrate that the theory I am affirming falls into none of today's categories-rather, that its very new truth, once it is firmly established, may open all our eyes.

It has happened in a rather natural way that all of the detailed mathematical discussion in this article is confined to Sections 1 and 3 . It does not follow that Sections 2 and 4 are self-contained; but they do carry a long way into the conceptual considerations set off by the odd-numbered sections, and they can, I think, be profitably reread in themselves.

The article's closing comments, in particular, are among the new points I am making for the first time in this writing. It is a striking fact that my contentions draw most forceful support from the quoted passage of Piaget, which contains one of his supremely sensitive observations on the growth of children-while he himself is obliged to interpret that observation in an altogether opposite sense, in proceeding according to the traditional conception of reality.

October, 1969

The quay,

San Francisco

\section{Introduction}

The presentation in the ensuing pages is divided into four parts. In Section I we proceed from the present day $\sigma$-field-real-valued-measure representation of a stochastic process to develop the intuitions that combine to produce the new kind of theorization we are pursuing. The notion of marginality is seen to be central in this intuitive build-up. In Section II we arrive at the consideration of a key question: the dynamics of such a proposed theory. It is noted that our efforts to discover a dynamical law within the $\sigma$-field-real-valued-measure framework have been without success, and we have more recently turned to investigating the possibility of a mathematically more exact representation of stochastic processes. Section III is devoted to outlining this mathematical work. In Section II also we take up the discussion of certain social phenomena which present themselves as striking examples of human behavior which is not suitably accounted for within the traditional scientific framework but which does seem to be well explained in the context of the theory we are proposing to establish. This discussion is completed in Section IV. 
In Section III we draw upon the purely mathematical device of inducing, for a $\sigma$-field-real-valued-measure structure, a representation in terms of a lattice of commuting closed linear manifolds in a unitary space and an adjunct 1-dimensional manifold in the space. The notion of marginality associated with $\sigma$-fields also translates into the unitary space setting. But now, once we are in this setting, several things appear. It suggests itself on the grounds of straight mathematical generalization to consider that pertinent eventualities may be represented by linear manifolds which are not all mutually commutative. In support of the meaningfulness of this direction of expansion of ideas there comes forward immediately the fact of quantum mechanics. The old notion of marginality now falls totally useless and another notion will have to be found to replace it. But this can be done only in conjunction with a new lattice structure admitting closed linear manifolds as elements but admitting also meets and joins of non-commuting manifolds. The investigation of such lattices is precisely what our current mathematical publications deal with. The adjunct 1-dimensional manifold referred to above suggests a somewhat surprising insight but one that commands attention. We take it seriously: the effect is, first, that probabilities no longer appear as fundamental, thus leaving eventualities and acts alone as the basic structural elements in the theory; and second, we are enabled to produce a guess as to what the dynamical law of the theory may look like.

The form of our proposed theory is so very different from the traditional scientific frameowrk that on that basis alone, even though the preicse (i.e., mathematical) substantiating details are not yet fully worked out, there are statements to be made about (in particular) human behavior which seem to shed light where there was none before. After having displayed in Section II the failings of traditional basic scientific conceptions, we go to some length in Section IV to show how our theoretical ideas, in comparison, appear to agree closely with the empirical evidence.

I.

To build the exposition of the body of ideas we wish to impart in this article, we can very suitably begin with certain insights regarding stochastic processes. But before that let us take a moment to clarify terminology. The expression "stochastic process" is understood by most people today to designate a mathematical entity. These people will then go on to say that "stochastic processes" may be used to represent or "to model" real phenomena. By contrast, in our language usage the stochastic process is the real phenomenon itself. Thus, for example, if we are involved in tossing a coin repeatedly and recording the head-ortail outcome at each toss, then this actual, on-going happening, this real proceed- 
ing, is a stochastic process: it is what we might call an ordinary coin-tossing process. If, in reference to this stochastic process, we write down a sequence of spaces, $\boldsymbol{\Omega}_{1}, \boldsymbol{\Omega}_{2}, \ldots$, each consisting of two points, and if with the $\sigma$-field of all subsets of each of these spaces we associate the uniform numerical normed measure, and with direct products of these measurable spaces we associate the product measures, then what we have thereby detailed is a mathematical description or representation of the ordinary coin-tossing process. This particular description, asserting unwavering fairness of the coin and full independence of tosses, may be exactly true or it may miss being accurate; in any case it is our considered guess at the "full particulars" of the process in question. In other words, there is a true description of the process and it is, presumably, in terms of sets and measures and outcomes; but there is in general no way of knowing for certain just which sets and which measures these may be so we must rest content with $a$ mathematical description of the process, not knowing whether or not we have in hand the, fully correct, mathematical description of the process.

Whatever be the class of real phenomena that we would want to call stochastic processes, it is today considered that their true mathematical description is in terms of $\sigma$-fields of subsets, normed numerical measures on these $\sigma$-fields, and outcomes. The description of a particular process would be given by the specification of a collection of spaces, say $\left\{\Omega_{s}, \mathrm{~s} \in S\right\}$, and, for each s $\in S$, a $\sigma$-field of subsets of $\Omega_{s}$, say $\mathscr{A}_{s}$. On each direct product of finitely many of the $\mathscr{A}_{s}$ there would be specified a normed numerical measure; say $\mu_{s_{1}, s_{2}, \ldots, s_{n}}$ on $\mathscr{A}_{s_{1}} \times \mathscr{A}_{s_{2}} \times \cdots \times \mathscr{A}_{s_{n}}$. These measures would satisfy the usual consistency conditions. Finally, a full description of the process would specify the outcomes in it, these being what constitute the past of the process. In this manner a total description of the process would be given. But there are also other modes of description. For example, certain collections of conditional measures of the process might be specified in place of some

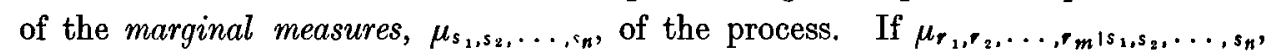
denotes the conditional measure on $\mathscr{A}_{r_{1}} \times \mathscr{A}_{r_{2}} \times \ldots \mathscr{A}_{r_{m}}$ relative to $\mathscr{A}_{s_{1}} \times \mathscr{A}_{s_{2}} \times \ldots$ $\mathscr{A}_{s n}$ for the process, then by way of illustration we may note that the specification

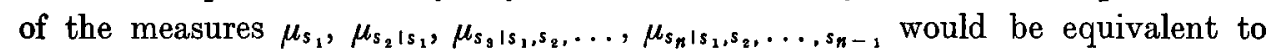

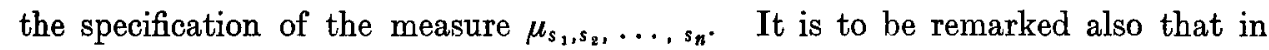
every case the spaces $\Omega_{s}$, the $\sigma$-fields $\mathscr{A}_{s}$ and the marginal measures can be combined to give an equivalent description in terms of a single space $\Omega$, a single $\sigma$-field, $\mathscr{A}$, in this space, and a measure $\mu$ on $\mathscr{A}$. The space $\Omega$ (which is the direct product of the spaces $\Omega_{s}$ ) is called the (comprehensive) space of the process and $A$ may be called the (comprehensive) $\sigma$-field of the process. The measure $\mu$ we call the comprehensive measure of the process; the measures $\mu_{s_{1}, s_{2}, \ldots, s_{n}}$ are called, more completely, marginal measures of $\mu$.

Further along in this article we shall take exception to the validity of the 
general mathematical description just given. But for the present let us suppose it to be correct and let us pursue its implications. The first piece of insight that it affords concerning stochastic processes begins with noticing that a remarkably small number of kinds of things make up the entirety of the mathematical description of a stochastic process. In fact, just three kinds of things: a set, a number associated with a set (=the value that the comprehensive measure associates with the set) and an outcome. The set in the mathematical context represents what in the real context we call an eventuality. The comprehensive measure value for a particular set represents what in the real context is called the (comprehensive) probability of the eventuality represented by that set. The word "outcome" is already interpretable in the real context, but its connotation is too restricted to permit the word to be of proper service; we prefer to speak of an act. (Thus, for example, in an ordinary coin-tossing process it is the entire tossing of the coin on, say, the third occasion and its landing head-up-let us suppose for definiteness that it has come to rest head up-that is an act of (or in) the process; the word "outcome" in its usual sense constrains us to speak of the head-up as the outcome of the third tossing. More generally, the word "outcome" connotes the consequence of a devised action; the word "act" does not suffer from this implication of directive human interference.)

From the mathematical structure we come to see, then, that a stochastic process is made up three kinds of entities: eventualities, probabilities and acts. Note, however, that it is not being affirmed here that these three conceptseventuality, probability, act-are to be taken as independent concepts in a fully fundamental presentation of a stochastic process. Indeed, our remark at the beginning of the preceding paragraph is to the point that we shall later find reason to believe that perhaps just the pair of concepts, eventuality and act, is all that enters into the totally fundamental explication of a stochastic process, and that probability is a derived concept. We are at this stage noticing simply that no more than the triplet of concepts-eventuality, probability, act-is needed to fully present a stochastic process.

There is not anything especially striking about the number three-as the number of a sufficiently large collection of concepts to explain a stochastic processas it refers isolatedly to one particular stochastic process or another. To say the same thing somewhat more graphically: if we think of stochastic processes as forming a collection, and we look no further into their interrelationships than to remark that they are all members of this collection, then it is not particularly surprising that each of them is explicable in terms of only three concepts. For, indeed, our traditional prejudice that sees no way around the need for vast numbers of basic concepts to explain greatly inclusive areas of behavior-that prejudice can continue to see itself satisfied in what would have to be said if one did proceed to 
elucidate the interrelations between stochastic processes. It is expected that one would be unavoidably compelled to introduce many, many new fundamental concepts in going on to detail the nature of the interconnections between stochastic processes. Either that, or be compelled to admit that only a limited array of phenomena are truly stochastic processes. But, in point of fact-tradition and all its power notwithstanding-neither of these compulsions appears to have to be inevitably submitted to. A fullness of insight suggests both that all real phenomena are stochastic processes and that the interrelationships between stochastic processes are entirely explainable in terms of nothing more than the above three concepts. (Therein lies the marvel of the smallness of the number three.)

Let us explain this double intuition. Take, for example, to begin with, some particular animal; let us say, the pet cat of Mr. Molnar who lives on Bela Bartok Avenue. And consider the stochastic process that might be called the daily indooroutdoor process of this cat. (Note that a stochastic process is an entirely specific phenomenon; it is not a class of phenomena. In mathematical representation the daily indoor-outdoor process of some other cat (or some dog or other household pet) might be identical with the daily indoor-outdoor process of Mr. Molanr's cat, but they are different stochastic processes.) In this stochastic process there is a collection of eventualities for each calendar day. An exmaple of an eventuality in one of these collections would be the following: "that the cat is out of the house three periods during this day, the first period starting between 7:00 hrs and 7:02 hrs. and ending between $7: 10 \mathrm{hrs}$. and $7: 13 \mathrm{hrs}$., the second period running from between 11:45 hrs. and 11:55 hrs. to between 14:05 hrs. and 14:45 hrs., and the third period going from between 19:00 hrs. and 19:15 hrs. to between 22:30 hrs. and 23:00 hrs." (Although this is the sort of verbal presentation that we customarily accept as a full description of the eventuality in question, it is in fact very far from a full description. A full presentation would include a description of the manner of observing and registering of the times referred to-that is, whether by some human being (who exactly?) who lets the cat in and out through the main door of the house, or by some automatic recording device perhaps which operates on a small door near the floor through which the cat has free access into and out of the house, or by whatever other means. A full presentation of the eventuality, if it could be given, would also detail further the cat's being "out of the house" during the three periods; for example, whether, during each period, the cat was totally outside in the sense of the door being closed behind him, or he was seated on the threshhold while the door remained open during the entire period. The point to be grasped here is that statements like "it is between 7:00 hrs. and 7:05 hrs." and "the cat is outside of the house" are vague idealizations and do not at all describe specific happenings or potential happenings; on the other hand, eventualities and acts are unique, fully specific real things. A little extended thinking in this direction soon reveals the suggestion 
that eventualities and acts are not in general finitely describable. In other words, there does not in fact exist, in general, a "full description" of an eventuality or an act.) In the mathematical representation of this d.i.o. process (the daily indoor-outdoor process of Mr. Molnar's cat) the eventualities just described which pertain to a particular day are represented by the sets of a $\sigma$-field of subsets of a space $\Omega_{s}$, a typical point of this space being a finite sequence $\left\langle k ; \alpha_{1}, \beta_{1} ; \alpha_{2}, \beta_{2} ; \ldots ; \alpha_{k}, \beta_{k}\right\rangle$ with $k$ a non-negative integer and the $\alpha$ 's and $\beta$ 's being real numbers in the closed interval $[0,24]$ such that $\alpha_{1}<\beta_{1}<\alpha_{2}<\ldots<\beta_{k}$; this typical point connotes the cat's being outside $k$ periods during the day, the first period being the time interval $\left(\alpha_{1}, \beta_{1}\right), \ldots$, the $k$-th period being the time interval $\left(a_{k}, \beta_{k}\right)$. Thus, for instance, the point $(3 ; 7.00,7.17 ; 11.84,14.5 ; 19.17,22.75)$ is one of the points of the set representing the eventuality we described in detail above. And that set itself is the collection of all points $\left(3 ; \alpha_{1}, \beta_{1} ; \alpha_{2}, \beta_{2} ; \alpha_{3}, \beta_{3}\right)$ such that

$$
\begin{array}{ll}
7 \leq \alpha_{1} \leq 7 \frac{1}{30}, & 7 \frac{1}{6} \leq \beta_{1} \leq 7 \frac{13}{60} ; \\
11 \frac{3}{4} \leq \alpha_{2} \leq 11 \frac{11}{12}, & 14 \frac{1}{12} \leq \beta_{2} \leq 14 \frac{3}{4} ; \\
19 \leq \alpha_{3} \leq 19 \frac{1}{4}, \quad 20 \frac{1}{2} \leq \beta_{3} \leq 21 .
\end{array}
$$

The pertinent $\alpha$-field, $\mathscr{A}_{s}$, of subsets of $\Omega_{s}$ may, for each index-value $\mathrm{s}$, be one that is very simply characterized; namely, the smallest $\sigma$-field containing all the sets of the very particular type of our example:-that is, a set whose points $\left(k ; \alpha_{1}, \beta_{1} ; \ldots\right.$; $\alpha_{k}, \beta_{k}$ ) are those such that $k$ has some constant value and each of the $\alpha_{i}$ and $\beta_{i}$, $i=1,2, \ldots, k$, varies in a given closed interval. For purposes of our present expository discussion we may rest content with this possibility for the $\sigma$-fields $\mathscr{A}_{s}$. Finally, then, to complete the description of the present d.i.o. process we must specify the probabilities. But to do this in any very explicit way would involve a mathematical discussion decidedly nonperfunctory, and hence lengthy, because of the fact that the component $\sigma$-fields $\mathscr{A}_{s}$ are somewhat complicated in structure. We shall therefore forego this explicitness and be satisfied that the probabilities are there even though not laid out in detail. Thus, we have the d.i.o. process now completely in view.

Consider next the gross morbidity process of Mr. Molnar's cat, or, for brevity, his g.m. process. By this we mean the process of day by day sickness or health of the animal. The qualification "gross" is intended to indicate that this process does not include eventualities (or acts) of, for example, close temperature readings by thermometer or medically precise analysis of symptoms, or measure of duration of affictions. Thus, for any particular day the eventualities of the process are only such as the following: "that the cat has a normal day with no noticeable distress"; 
"that he spends an unusual amount of time biting and scratching at a small area on his body just under the right fore-paw"; "that he is steadily fussy and makes his claws felt more than usual on being approached"; and so on. There are, in fact, only finitely many of the kind of eventualities we have in mind. Therefore, the mathematical representation of this g.m. process each day has associated with it a space $\Omega^{\prime}{ }_{s}$ of finitely many points, and the eventualities of the process for that day are in one-to-one correspondence with the collection of all subsets of $\Omega^{\prime}{ }_{s}$; the latter is the pertinent $\sigma$-field $\mathscr{A}^{\prime}{ }_{s}$ in the present situation. The probabilities-which we shall here again not bother to present in any greater detail-might in the present case be insightfully specified in terms of the measure $\mu_{1}^{\prime}$ on $\mathscr{A}^{\prime}{ }_{1}$ and the sequence of conditional measures $\mu_{211}^{\prime}, \mu_{311,2}^{\prime}, \mu_{411,2,3}^{\prime}, \ldots$.

One could go on to identify, and to describe in greater or lesser detail, other processes of Mr. Molnar's cat, as we have done with the d.i.o. process and the g.m. process. For example, there is the cat's nutrition process which accounts for the kinds and quantities of food he ingests throughout each day; there is his cardiovascular process that explains the interconnected functioning of the heart and the coursing of the blood through the system of blood vessels; there is his social process accounting for his encounters, friendly and hostile, throughout each day with other animals and with human beings; and so on and on. In each of these cases there is a phenomenon concerned with Mr. Molnar's cat and we conceive ourselves able to see through to its formulation in terms of $\sigma$-fields of subsets representing the eventualities that pertain, and probability measures on these $\sigma$ fields. Thus-with our tentative understanding that the exact representation of a stochastic process is always in terms of $\sigma$-fields and real-valued measures-it is very natural to take the intellectual jump and consider that all the real phenomena involving Mr. Molnar's cat are stochastic processes. And indeed we do now make this affirmation.

Now, there is an immediate question of self-consistency regarding the affirmation just made. Take, for example, the g.m. process and the nutrition process. We came upon these two phenomena separately as we were thinking into the nature of Mr. Molnar's cat, and we saw each of them in itself, therefore, as a stochastic process. But it is just as true that there is $a$ phenomenon of sickness-healthnutrition pertaining to this cat, and we might have come upon it in our analytical deliberations on the cat. In other words, it is just as validly a single phenomenon regarding this cat that he has certain patterns of feeding and general well-being as it is a single phenomenon that he has a certain pattern of general well-being and a single phenomenon that he has a certain pattern of feeding. This being the case, our contention that all phenomena are stochastic processes then obliges us to demonstrate that the combined phenomenon of general well-being and nutrition also has the usual structure in terms of $\sigma$-fields and real measures. The question 
of consistency is the question of whether or not this can be true while the two separate partial aspects of this combined phenomenon definitely are of the $\sigma$-fieldreal-measure structure. What makes the question non-trivial is that-clearly-the exact detail in the mathematical structure of the combined phenomenon must in itself engender the exact detail in the structure of each of the two separate subphenomena. That is, the combined phenomenon completely comprehends each of the separate phenomena, and the exact description must reflect this.

The answer to this question of consistency is right at hand: the combined g.m.nutrition process is a joint stochastic process of which the g.m. process and the nutrition process are two marginal processes, in the standard sense of the calculus of probabilities. Thus, the consistency question, potentially a very difficsult one, turns out to be not difficult at all. The calculus of probabilities provides an answer in one of its most immediately available concepts: marginality.

What has here been seen for the g.m. process and the nutrition process extends to (at least countable) collections of processes in general, the mathematical notion of marginality being the key to the interrelationships between the processes. That is, in a general way, processes are related through being marginals of joint processes. This statement, taken to full generality beyond just Mr. Molnar's cat, is the substantiation of our earlier assertion that the interrelationships between stochastic processes are entirely explainable in terms of nothing more than the structural elements: eventualities, probabilities and acts.

We have still to explain our other stated intuition, namely, that all real phenomena are stochastic processes. To do this let us continue our build-up. We have been dealing with Mr. Molnar's cat and we have come to the point of asserting that all the real phenomena involving this cat are stochastic processes. We would, of course, make the same assertion for any real "entity": the automobile parked down at the corner, the sun, the statue in the living room, Mrs. Ferenc who lives on the next street, etc., etc. But there is even further to go. According to the preceding discussion there is no point at which the phenomena involving Mr. Molnar's cat cease to aggregate into a single joint stochastic process. This is to say, then, that there is nothing about the cat that brings to its identity any portion of structure that is not stochastic process structure. The implication is therefore quite simply this: the cat is itself a stochastic process. By the same token, the automobile, the sun, the statue, Mrs. Ferenc-these are all stochastic processes. And our unified picture does not stop there, either. Mr. Molnar's cat is a stochastic process and Mr. Molnar is a stochastic process. But also this pair of beings is a stochastic process: it is a joint process of which Mr. Molnar and the cat separately are marginal processes. Going on still further, the house in which Mr. Molnar lives with his cat is a stochastic process. The triplet which is the house, Mr. Molnar and the cat is a stochastic process-commonly called "the Molnar house- 
hold"-and it is a joint process having the house as a marginal process. The housecat pair is another marginal of it, as is the cat itself. And so on. The pattern of structure we are exemplifying here is now affirmed to be without exception. Thus, in the fullest sense of the phrase, we are saying that all real phenomena are stochastic processes. And if it is sensible to talk about "all of reality" then we must say that it is one grand stochastic process.

\section{II.}

With the currently conceived mathematical representation-that is, the $\sigma$-fieldreal-valued-measure structure-of stochastic processes. we have, in the preceding section, come upon the intuitions that all real phenomena are stochastic processes and that they are interstructured in being marginal processes of joint processes. We stressed the implication in this that all real description is renderable ultimately in terms of eventualities, probabilities and acts. In other words-and to express it grossly-everything is made up of eventualities, probabilities and acts. Now, it is deep in the Western scientific tradition that this last statement is looked upon as giving a merely derivative comment on reality. It is not seen as speaking at the fundamental level about the nature of things. The fundamental picture that persists is rather one of a space-time framework within which there exist ultimate particle-field entities, and all real structure is in terms of these in the last analysis. Accordingly, eventualities and acts are viewed as accountings of potential and actual activities and interplays of fundamental entities. They are far form being considered fundamental entities themselves. Even more, they are, in this traditional structural picture, not conceivable as having any objective identity on a par with the space-time continuum or with particles or energetic fields: they come to be known as "logical propositions."

In our view the true story of real structure is just the reverse. It is eventualities and acts that are the fundamental, objective, real entities, and all the make-up of real phenomena, of real things, is of these as the ultimate constitutent elements. (Probabilities are not included in this statement for the reason that will emerge in Section III.) Thus, our understanding of the above statement--"everything is made up of eventualities, probabilities and acts" (or rather, in the light of what we find in Section III, "everything is made up of eventualities and acts")-is that it refers wholly to objective reality; it says what are the basic kernels of being:-these things exist, they "are there", and their structured aggregates are all the things and goings-on of reality.

This theoretical position we have just described is decidedly non-trivial. It is not just a gratuitous "other point of view." It has serious implications that go distinctly contrary to traditional understanding, to traditional science. New theorizing aims at probing deeper into the nature of things, at expressing more and 
more completely the dynamics of reality. This effort of a theory is embodied in its dynamical law which is operative on the basic data as characterized by the theory and produces assertions as to what acts will be. In the theoretical framework that we are putting forward the basic data are eventualities, probabilities and acts (with probabilities later to he dropped as basic), and so the dynamical law of the theory will be operative on these. This is a circumstance which is far different from anything to be found in theorization up to the present time. Currently, probability "theory" is not a theory at all in this dynamical sense; it has no dynamical law. It is only a calculus of frequencies. It proceeds from the recognition of one empirical fact: that in an indefinite sequence of independent, "identical" stochastic situations the relative frequencies of actualization of any particular kind of eventuality appear to "converge" to a definite number. However, it does not explain this dynamical fact; it merely accepts it in a post-mortem way and then goes on to calculate other related "long-run" frequencies. Current probability "theory", which is truly only a "calculus of probabilities", simply rides along with the dynamical theories of the era and provides its mathematical services.

What, then, is the dynamical law in our theory? If this question were easy to find the answer to, or even only moderately difficult, our research might already, some time ago, have culminated in the arrival at our goal of a fully elaborated mathematical theory. For, there is a great deal of motivating intuitive content in the present mathematical representation of stochastic processes, wherein the probability of an eventuality suggests itself as the relative propensity of this eventuality to actulaize. (This conception emerged from the earliest stages of our investigations, when we were deliberating on the notion of utility that economists attempt to capture in their theorizing; we find utility and probability to be the very same thing. The article [6] gives an account of our thinking on this.) But all of our efforts to formulate a dynamical law within the $\sigma$-field-real-valued-measure context failed. (There is reason for rejoicing in this failure: it means that we may yet one day see the most complete kind of substantiation of the intuition that man, in his intellectuality, goes too far in applying numbers to measure phenomena.) A negative result in a search of this kind throws one back on one's confidence that the truth, however difficult it is to discover, is, once found, always more exicting than the cleverest of our false conjectures. And to this is to be added the renewed pleasure of the search itself when the trail seems to be getting warm again. In the recent past we have gone beyond the failure, to a new direction of investigation. The $\sigma$-field-real-valued-measure representation of stochastic processes is abandoned as a universal fact and a more general kind of mathematical representation of stochastic processes is proposed and studied. (Items [8], [9], [10] and [11] of the References are the initial publications in this line of research.) Within this new context it seems that it may be possible to formulate a dynamical law; 
at any rate, we have been able to make a tentative suggestion. In Section III we shall outline this latest work.

Our new theoretical position has another immediate implication which is notable for the degree to which it differs with classical understanding and thereby correctly accounts for certain phenomena in human behavior. We are seeing in the world today, especially among the young people, a very extensive personal unrest and search for change. As always in an upheaval of this magnitude there is a broad spectrum of motivations among the active participants. But it has begun to emerge now as definite and undeniable that at the heart of all this stirring there is a sincere impulsion that is neither identical with, nor defines itself as being in opposition to, any particular philosophy or any particular ideology. It is a force coming directly out of the feelings of numerous human beings, expressing itself in several forms: in the explicit cry for a greater sense of self, in the insistence on universal respect for human dignity, in the urging that man cease his brutality to man, in the advocacy of more loving among people and the bold efforts at doing so, in the undertaking of all kinds of projects to increase human contact and cooperation. There has always been available the evidence that a greater feeling of completeness, of personal fulfillment, results from increased and more concerned and intimate human contact. But its significance has been minimized; it has never been understood. Now today, when on a vast scale people's internal tensions are mounting to the bursting point, and the gnawings in their stomachs and in their hearts are biting so deep that neither diversions of attention nor the most trusted old spurious remedies can competently work the illusion of reliefso powerful is the oppression in modern times of the combined galloping technology, runaway overpopulation, rampant ecological destruction, unrelenting threat of nuclear holocaust, etc., etc.-today, vast numbers of people are finding release and elevation only in drawing close to each other, and we are challenged to understand the phenomenon. They gain that needed individual sense of fullness of being solely through developing ties with others, while rejecting the values of possession. They reject the unrestrained freedom to pursue possession of material things, and equally well they reject any principle of distribution of material things as at the basis of their seeking; they reject materiality altogether. And they succeed in finding the personal expansivness they crave. How can we explain this enigma? For, there is indeed an enigma here. There is an enigma because of the nature of traditional basic scientific conceptions and because of our indoctrination in them. Out of these conceptions it follows that a man cannot, with consistency, freely pursue both his own fulfillment and a deep concern for others. That is the necessary conclusion that is drawn from the idea that fundamentally things exist in space-time. In this conception the identity of a thing, of a system, of a human being, is found in its physico-temporal extension. The greater this 
extension, the greater the identity. This is the logic which, working tacitly, has compelled men to compete heartlessly for possessions, for status, for prestige. The competition comes into being because it is in the nature of physical extension that a portion of space or of material that strictly belongs to one man does thereby strictly not belong to another man. The enigma expresses itself also in men's finding that such physical accruals to (and hence extensions of) the physical self do not after all produce any reliable enhancement of the substance of fulfillment as verified by one's own feelings. (The wealthy find themselves offended by the snobbery of the wealthier; the accumulation of physical possessions by some to the exclusion of others eventually leads-as we are seeing today-to militant reactions which, in themselves and in their diverse implications, leave the privileged person in some consternation about who he really is (-picture, for example, the suburban resident of a demonstration-ridden city who one day while in mid-town on business finds himself quite by accident in the midst of a surging mob and along with a number of demonstrators is rounded up in a police sweep of the area; picture him saying to the police, "You can't arrest me. Do you know who I am?"-); men in prestigious positions, in industry, government, etc., are now commonly known to be plagued with the signs of self-doubt: overriding tension, stomach ulcers, autocratic behavior, etc., etc.; soaring rates of divorce, of alcoholism, of teen-age flight from home and family-these tell of myriad cases of stunning blows to selfimage.) That pernicious logic of greater physico-temporal extension implying greater identity produces equally enigmatic results for those who live under more controlled conditions. That false logic says that there can be nothing left to be desired by individuals if there is equal, or some quasi-equal, distribution of physical possessions, for then the ultimate possible justice has been done to the personality of every man. And yet men find their insides telling them that there is more to personal fulfillment; they cry out about impoverishment of the spirit and they strain after something more. The enigma is still there.

Here we have seen, thus, three distinct forms of contradiction to the traditional scientific fundamental that identity resides in physico-temporal extensionthree contradictions markedly observable in the world today. There are those who reject this principle utterly and find increased sense of self-fulfillment nevertheless; there are those who follow the principle fairly freely, under conditions of relatively little individual restraint, and who find it does not produce the promised results; and finally there are those who live under the "optimal solution" derived from the principle, and who likewise find that promised personal results are not forthcoming. These emprical facts are forceful evidence of the invalidity of traditional fundamental scientific conceptions. By contrast-as we have hinted above-the new fundamental structural conception that we are putting forward does properly account for all this emprical evidence. We shall elaborate this in Section IV 
below. (We have discussed this point at some length also in the articles [6] and [7].)

\section{III.}

In the preceding sections we have seen that the mathematics of the current calculus of probabilities would appear to afford us the possibility of a consistent, total build-up of real structure on the basis of eventualities and acts and probabilities exclusively as fundamental. Crucial for this development was the notion of marginality as it is given in the present-day probability calculus; it provided the understanding of the inter-structuring of stochastic processes. Let us take a look at this notion of marginality. For definiteness and simplicity consider the g.m. process and the nutrition process of Mr. Molnar's cat. (In discussing these we are, moreover, treating the special case of two stochastic processes that have no eventuality in common; we shall comment on the general case further on below.) In mathematical representation each of these two processes is depicted by a sequence of finite spaces, one for each day, the $\sigma$-field of all subsets of each space denoting the eventualities on that day; and there is the sequence of conditional measures for each process. Specifically (starting with some particular day as the first), let the g.m. process have the spaces $\Omega_{s}^{\prime}, \mathrm{s}=1,2, \ldots$; the $\sigma$-fields $\mathscr{A}^{\prime}{ }_{s}, \mathrm{~s}=1,2, \ldots$, in these spaces; and the measures $\mu_{1}^{\prime}, \mu_{211}^{\prime}, \mu^{\prime}{ }_{\mathbf{3} 1,2}, \ldots$ Similarly let $\boldsymbol{\Omega}^{\prime \prime}, \mathrm{s}=1,2, \ldots$, and $\mu_{1}^{\prime \prime}, \mu^{\prime \prime}{ }_{211}, \mu^{\prime \prime}{ }_{311,2}, \ldots$ be the representation elements for the nutrition process. Then, the joint g.m.-nutrition process has for its spaces the direct products $\Omega^{\prime}{ }_{s} \times \Omega^{\prime \prime}{ }_{s}$, and for its $\sigma$-fields in these respective spaces the direct products $\mathscr{A}^{\prime}{ }_{s} \times \mathscr{A}^{\prime \prime}{ }_{s}$; in the present case of finite spaces each $\mathscr{A}^{\prime}{ }_{s} \times \mathscr{A}^{\prime \prime}{ }_{s}$ turns out to be just the $\sigma$-field of all subsets of $\Omega^{\prime}{ }_{s} \times \Omega^{\prime \prime}{ }_{s}$. In general, $\mathscr{A}^{\prime}{ }_{s} \times \mathscr{A}^{\prime \prime}{ }_{s}$ is the $\sigma$-field generated by (i.e., the smallest $\sigma$-field including) the class of all subsets of $\Omega^{\prime}{ }_{s} \times \Omega^{\prime \prime}$ s of the form $A^{\prime}{ }_{s} \times A^{\prime \prime}{ }_{s}$, where $A^{\prime}{ }_{s} \in \mathscr{A}^{\prime}{ }_{s}$ and $A^{\prime \prime}{ }_{s} \in \mathscr{A}^{\prime \prime}{ }_{s}$. For some, or any, particular index s, $\Omega^{\prime}{ }_{s}$ may have a singleton set (i.e., a set consisting of a single point) $A_{s}{ }^{(1)}$ ' representing the eventuality "that the cat has a bloodshot eye", and another, $A_{s}{ }^{(2)}$ ', representing the eventuality "that the cat's left front paw is bleeding"; and $\Omega^{\prime \prime}{ }_{s}$ may have singleton sets $A_{s}{ }^{(1)}$ " representing the eventuality "that the cat eats six ounces of tuna during the day", and $A_{s}{ }^{(2)}$ " representing the eventuality "that the cat eats four ounces of tuna and three ounces of meal during the day". Then $\mathscr{A}^{\prime}{ }_{s} \times \mathscr{A}^{\prime \prime}$ s contains, for example, the (singleton) set $A_{s}{ }^{(1)^{\prime}} \times A_{s}(2)^{\prime \prime}$ representing the eventuality "that the cat has a bloodshot eye and he eats four ounces of tuna and three ounces of meal during the day", and the (non-singleton) set $\left.\left(A_{s}{ }^{(1)^{\prime}} \times A_{s}{ }^{(1)}\right)^{\prime \prime}\right) \cup\left(A_{s}{ }^{(2)} \times A_{s}{ }^{(2)^{\prime \prime}}\right)$ representing the eventuality "that the cat has a bloodshot eye and eats six ounces of tuna during the day, or his left front paw is bleeding and he eats four ounces of tuna and three ounces of meal during the day". Finally, the joint process has a 
sequence of measures: $\mu_{1}, \mu_{211}, \mu_{3 \mid 1,2}, \ldots$ The measures $\mu^{\prime} .1 \ldots$ and $\mu^{\prime \prime} .1 \ldots$, with the exception of those having conditioning sets of comprehensive measure zero, are determined by these measures $\mu_{.1 \ldots}$. This determination may be seen most efficiently in the following way: from the measures $\mu_{.1} \ldots$. let there be formed the comprehensive measure, say $\mu$, for the joint process; from $\mu$ form the conditional measure relative to the sub- $\sigma$-field $\left(\mathscr{A}^{\prime}{ }_{1} \times \Omega^{\prime \prime}{ }_{1}\right) \times\left(\mathscr{A}_{2}^{\prime}{ }_{2} \times \Omega^{\prime \prime}{ }_{2}\right) \times \ldots \times\left(\mathscr{A}^{\prime}{ }_{n-1} \times \Omega^{\prime \prime}{ }_{n-1}\right) \times$ $\left(\Omega^{\prime}{ }_{n} \times \Omega^{\prime \prime}{ }_{n}\right) \times \ldots$ of the $\sigma$-field of the joint process; lastly, restrict this conditional measure to the sub- $\sigma$-field $\left(\Omega_{1}^{\prime} \times{\Omega^{\prime \prime}}_{1}\right) \times \ldots\left(\Omega^{\prime}{ }_{n-1} \times \Omega^{\prime \prime}{ }_{n-1}\right) \times\left(\mathscr{A}^{\prime}{ }_{n} \times \Omega^{\prime \prime}{ }_{n}\right) \times\left(\Omega^{\prime}{ }_{n+1} \times\right.$ $\left.\Omega^{\prime \prime}{ }_{n+1}\right) \times \ldots$ of the joint process $\sigma$-field; the measure thus resulting in the case $n=1$ is precisely $\mu_{1}^{\prime}$, and for $\mathrm{n}>1$ is $\mu_{n \mid 1,2}^{\prime} \ldots, n-1$. Similarly the $\mu^{\prime \prime}, 1 \ldots$ are obtained. In the present situation of finite spaces $\Omega^{\prime}{ }_{s}$ and $\Omega^{\prime \prime}{ }_{s}$ there is a much more explicit, sequential procedure for obtaining the $\mu^{\prime}, 1 \ldots$ and the $\mu^{\prime \prime}, 1 \ldots$ from the $\mu_{.1} \ldots$. However, there is no need for us to enter into this matter here.

If we deal exclusively with the comprehensive spaces, $\Omega^{\prime}, \Omega^{\prime \prime}$, and $\Omega$ of the g.m. process, the nutrition process and the joint g.m.-nutrition process, respectively, and with their respective comprehensive $\sigma$-fields, $\mathscr{A}^{\prime}, \mathscr{A}^{\prime \prime}$ and $\mathscr{A}$ and their comprehensive measures, $\mu^{\prime}, \mu^{\prime \prime}$ and $\mu$ then the marginality in this structuring is much more immediately apparent. We have $\Omega=\Omega^{\prime} \times \Omega^{\prime \prime}, \mathscr{A}=\mathscr{A}^{\prime} \times \mathscr{A}^{\prime \prime}$, and if $B$ and $C$ are elements of $\mathscr{A}^{\prime}$ and $\mathscr{A}^{\prime \prime}$ respectively, we have $\mu^{\prime}(B)=\mu\left(B \times \Omega^{\prime \prime}\right)$ and $\mu^{\prime \prime}(C)=$ $\mu\left(\Omega^{\prime} \times C\right)$. The $\sigma$-field $\widetilde{A^{\prime}}$ (denoted also by $\mathscr{A}^{\prime} \times \Omega^{\prime \prime}$ ) of sets in $\mathcal{A}^{\prime}$ which are of the form $B \times \Omega^{\prime \prime}$, with $B \in \mathscr{A}^{\prime}$, is isomorphic to $\mathscr{A}^{\prime}$ under the correspondence $B \leftrightarrow B \times$ $\Omega^{\prime \prime}$, and therefore we may, in customary fashion, take $\widetilde{A^{\prime}}$, just as well as $\mathscr{A}^{\prime}$, to represent the collection of eventualities of the g.m. process. We do similarly for the nutrition process with the correspondingly defined $\sigma$-field $\widetilde{A}^{\prime \prime}$. These two processes can then be viewed as marginal processes of the joint process in that their collections of eventualities comprise sub- $\sigma$-fields of the joint $\sigma$-field $A$ and their measures are restrictions of the joint measure $\mu$ to these sub- $\sigma$-fields. But this is not yet the total characterization of the present situation. To get at this, let $\omega^{\prime}$ and $\omega^{\prime \prime}$ denote points of $\Omega^{\prime}$ and $\Omega^{\prime \prime}$, respectively. Consider the function $\mathrm{g}_{1}$ on $\Omega$ to $\Omega^{\prime}$ defined by $g_{1}\left(\left(\omega^{\prime}, \omega^{\prime \prime}\right)\right)=\omega^{\prime}$; this is a measurable function on $(\Omega, \mathscr{A})$ to $\left(\Omega^{\prime}\right.$, $\left.\mathscr{A}^{\prime}\right)$. The sub- $\sigma$-field $\tilde{A}^{\prime}$ now appears as the $\sigma$-field induced by the function $\mathrm{g}_{1}$. That is, $\mathscr{A}_{1}^{\prime}$ is the sub- $\sigma$-field of $\mathscr{A}$ consisting of all sets of the form $\mathrm{g}_{1}^{-1}(B)$ with $B \in \mathscr{A}^{\prime}$. Similarly, $\mathscr{A}^{\prime \prime}$ is the $\sigma$-field induced by the function $\mathrm{g}_{2}$, defined by $\mathrm{g}_{2}\left(\left(\omega^{\prime} . \omega^{\prime \prime}\right)\right)=\omega^{\prime \prime}$, which is a measurable function on $(\Omega, \mathscr{A})$ to $\left(\Omega^{\prime \prime}, \mathscr{A}^{\prime \prime}\right)$. The two functions $\mathrm{g}_{1}$ and $\mathrm{g}_{2}$ are quite special measurable functions: they are the two coordinate functions on the binary, measurable direct product $\left(\Omega^{\prime}, \mathscr{A}^{\prime}\right) \times\left(\Omega^{\prime \prime}, \mathscr{A}^{\prime \prime}\right)$. Thus, the full depiction of the present marginality structure is this: the g.m. process and the nutrition process are marginal processes of the joint process in that their collections of eventualities "are" the sub- $\sigma$-fields of $\mathscr{A}$ (=the joint $\sigma$ field) induced by the two coordinate functions of the direct product space, and 
their measures are the restrictions of the joint measure $\mu$ to these sub- $\sigma$-fields.

This is, then, in detail, an example of the marginality notion that the present-day calculus of probabilities holds out immediately for understanding the interstructuring of stochastic processes. Is it the correct explanation of interstructure, or is it not ? In our discussion up to this point we have already seen a couple of reasons to doubt the correctness, or at least the general adequacy, of this explanation. For one thing, in Section I we were obliged to be a little vague about the fitting together, under this notion of marginality, of infinitely many stochastic processes: we had to note parenthetically that our suggestion was valid at least in the countable case. This qualification had to be inserted because of the limitation of general validity of constructs in the calculus of probabilities to countable set operations. A second suggestion of doubt came in Section II with our noting that it does not seem possible to formulate a dynamical law entirely within the context of $\sigma$-fields and real-valued measures. Still a third technical fact generates reservations; this one is tied to the deliberations above involving conditional probabilities. In the probability calculus the general definition of conditional probabilities is made via the Radon-Nikodym theorem, and it proffers, not a set-function on the $\sigma$-field for each point in the space, but a point-function on the space for each set in the $\sigma$ field. It is then a further question whether or not these point-functions, with admissible modifications, constitute a single function on the direct product of the space and the $\sigma$-field whose every section, for a given point of the space, is a setfunction which is a measure. The fact of the matter is that this is not true in general. While this difficulty does not enter in the case of the finite spaces we dealt with hereabove, it is a difficulty that intrudes to deny the concise generality that would be demanded of a theory; it is simply a fact that conditional probability "distributions" are not always measures.

Confronted by this array of negative indications-which are there in spite of the suggestiveness and the apparent naturalness of the standard notion of marginalitywe are motivated to look for other possibilities to explain the interstructuring of stochastic processes. One tentative possibility occurs to us as calling for examination-in spite of the above objections-when we look back at our final statement above giving the depiction of the marginality structure in the case of the g.m. process and the nutrition process. The suggestion is that perhaps we have only to drop the condition that the two sub- $\sigma$-fields be induced by coordinate functions. That is, the definition of marginality is widened somewhat, as follows: one stochastic process is said to be a marginal of a second stochastic process if they have mathematical representations $(\Omega, \mathscr{B}, \nu)$ and $(\Omega, \mathscr{A}, \mu)$, respectively, with $\mathscr{B} \subseteq \mathscr{A}$ and $\nu=$ the restriction of $\mu$ to $\mathscr{B}$. Then, two processes would be interstructured simply in that they are two marginal processes in this sense of some third process. And indeed it takes this broader definition of marginality to account for inter- 
structuring in the case of two processes which have eventualities in common. But we discover quite readily in studying the case of two processes which have no eventuality in common, as with the g.m. process and the nutrition process, that this broader notion of marginality introduces nothing new at all. It is found through a natural isomorphism that the joint g.m.-nutrition process is once again represented by a direct product of measurable spaces, namely, the range spaces of suitably chosen inducing functions-even if these functions are not coordinate functions.

Marginality notions within the $\sigma$-field-real-valued-measure framework do not, then, at all, lead us out from under the stated criticisms. Evidently we must, if possible, go beyond that framework altogether. But is there any place else to go ? The answer to this question is yes, and we can come to see it through re-examining the structural situation we have just discussed. Consider again, therefore, two stochastic processes supposed representable in the $\sigma$-field-real-valued-measure formalism; let such representation in comprehensive form be $\left(\Omega^{\prime}, \mathscr{A}^{\prime}, \mu^{\prime}\right)$ and $\left(\Omega^{\prime \prime}, \mathscr{A}^{\prime \prime}\right.$, $\left.\mu^{\prime \prime}\right)$. These two processes are marginals, in the sense of the preceding paragraph, of another process, represented by $(\Omega, \mathscr{A}, \mu)$, say. Thus, the prime process has a representation $\left(\Omega, \mathscr{F}^{\prime}, \nu^{\prime}\right)$, and the double-prime process has a representation $\left(\Omega, \mathscr{B}^{\prime \prime}, \nu^{\prime \prime}\right)$, where $\mathscr{B}^{\prime}$ and $\mathscr{B}^{\prime \prime}$ are sub- $\sigma$-fields of $\mathscr{A}$ and $\nu^{\prime}$ and $\nu^{\prime \prime}$ are the restrictions of $\mu$ to $\mathscr{B}^{\prime}$ and $\mathscr{B}^{\prime \prime}$ respectively. The $\sigma$-fields $\mathscr{A}^{\prime}$ and $\mathscr{B}^{\prime}$ are isomorphic and $\mu^{\prime}$ and $\nu^{\prime}$ agree on corresponding sets. Similarly for $\mathscr{A}^{\prime \prime}, \mathscr{B}^{\prime \prime}$ and $\mu^{\prime \prime}, \nu^{\prime \prime}$. In view of these isomorphisms we may simply take $\left(\Omega^{\prime}, \mathscr{A}^{\prime}, \mu^{\prime}\right)$ to be $\left(\Omega, \mathscr{B}^{\prime}, \nu^{\prime}\right)$, and $\left(\Omega^{\prime \prime}, \mathscr{A}^{\prime \prime}, \mu^{\prime \prime}\right)$ to be $\left(\Omega, \mathscr{B}^{\prime \prime}, \nu^{\prime \prime}\right)$; and therefore all of our ensuing considerations will deal with the one space $\Omega$.

Let $\mathfrak{S}$ denote the unitary space of equivalence classes of square-integrable, complex-valued functions on the measure space $(\Omega, \mathscr{A}, \mu)$. For any $A \in \mathscr{A}$ let $\mathfrak{M}_{\boldsymbol{A}}$ denote the c.l.m. (i.e., closed linear manifold) of all (equivalence classes of) functions which vanish a.e. in $A^{c}$ (the complement of $A$ ). The collection $\left\{\mathfrak{M}_{A} \mid A \in \mathscr{A}\right\}$ forms a $\sigma$-complete lattice, $\mathcal{L}_{\mathscr{A}}$, with g.l.b.=intersection and l.u.b.=closed linear span. This is a consequence of the following identities which show, in fact, that this lattice is essentially isomorphic to the $\sigma$-field $\mathscr{A}$ :

$$
\begin{aligned}
& \bigcap_{i=1,2, \ldots} \mathfrak{M}_{A_{i}}=\mathfrak{M}_{i=1,2, \ldots} A_{i}, \\
& {\left[\underset{i=1,2, \ldots}{\bigcup} \mathfrak{M}_{A_{i}}\right]=\mathfrak{M}_{i=1,2, \ldots}{ }_{A_{i}} .}
\end{aligned}
$$

(The notation [ ] means "closed linear manifold spanned by.") A handy terminological device is to say that two c.l.m.'s commute if the projections of which they are the ranges commute. Let $E(A)$ denote the projection onto $\mathfrak{M}_{A}$. It is a fact that all the $E(A), A \in \mathscr{A}$, are mutually commutative. Thus, all the $\mathfrak{N}_{A}$ commute with each other. As a function on $\mathscr{A}, E(\cdot)$-or simply $E$-is what is called a spectral measure. 
In what has been described in the preceding paragraph we see that there is produced an alternative representation of the collection of eventualities in the process initially represented by $(\Omega, \mathscr{A}, \mu)$. This new representation is the ordinary lattice (i.e., with g.l.b. and l.u.b. defined as above) of the spectral manifolds of a particular spectral measure in a unitary space. We can take still further advantage of this unitary space to obtain an in-context representation of the measure $\mu$; that is, we are not obliged to present the measure merely as a function on the collection of spectral manifolds. The inner product $(\phi, \psi)$ of two elements, $\phi$ and $\psi$, in $\mathfrak{g}$ is $\int \phi \bar{\psi} \mathrm{d} \mu$. Therefore, if we let $\psi_{0}$ denote the function which is everywhere equal to 1 in $\Omega$, we have, for every $A \in \mathscr{A}$, that $\left\|E(A) \psi_{0}\right\|^{2}=\mu(A)$. This fact can be described as follows: there is an element of norm 1 in $\mathfrak{g}$ such that the $\mu$-value associated with any particular c.l.m. is the squared norm of the projection of that element onto this c.l.m. Thus, the measure $\mu$ shows up as already contained in the unitary space structure: it is in the relationships between the c.l.m.'s representing the eventualities and a certain 1-dimensional c.l.m. (namely, the one determined by $\psi_{0}$; any element of norm 1 in this c.l.m. will do the same job as $\left.\psi_{0}\right)$.

To sum up: our stochastic process which has been presumed representable by $(\Omega, A, \mu)$ has bene found to be alternatively representable as a lattice $\mathcal{L}_{*}$ of commutative c.l.m.'s in a unitary space together with an adjunct 1-dimensional c.l.m. in the space.

Within this same unitary space structure our two marginal processes, represented initially by $\left(\Omega, \mathscr{B}^{\prime}, \nu^{\prime}\right)$ and $\left(\Omega, \mathscr{B}^{\prime \prime}, \nu^{\prime \prime}\right)$, get representations as lattices $\mathcal{L} \mathscr{\mathscr { O }}^{\prime}$, and $\mathcal{L} \mathscr{P}^{\prime \prime}$, respectively, and with the same adjunct 1-dimensional c.l.m. as in the case of $\mathcal{L}_{\mathscr{x}}$. Furthermore, $\mathcal{L}_{\mathscr{B}^{\prime}}$, and $\mathcal{L}_{\mathscr{J}^{\prime \prime}}$ are sub-lattices of $\mathcal{L}_{\mathscr{A}} ;$ hence, not only is each of them a lattice of commutative c.l.m.'s, but also every c.l.m. in one of them commutes with every c.l.m. in the other.

We have now reached the jumping-off place for going beyond the $\sigma$-field-realvalued-measure framework. We have found an equivalent formulation of this framework in the context of a unitary space and in terms of the natural configurations and operations in that space. The eventualities in a process are represented by the ordinary lattice of spectral manifolds of a certain spectral measure, and there is a concomitant 1-dimensional manifold which yields the probabilities, that is, the values of the measure $\mu$, through its geometrical relationship with the spectral manifolds. In this form of representation the interstructuring of two stochastic processes is expressed in their representative lattices being sub-lattices of a third lattice representing an inclusive third process, and in there being a common adjunct 1-dimensional manifold giving the probabilities in the three processes as described. It is clear that the previous concept of marginality translates into the present context as follows: Let $\mathcal{L}$ and $\mathcal{L}^{\prime}$ be the lattices of spectral manifolds of two 
spectral measures, and let $\mathrm{n}$ and $\mathrm{m}^{\prime}$ be 1 -dimensional linear manifolds; then, the stochastic process represented by $\left(\mathcal{L}^{\prime}, \mathfrak{m}^{\prime}\right)$ is said to be a marginal process of the stochastic process represented by $(\mathcal{L}, \mathfrak{m})$ if $\mathcal{L}^{\prime}$ is a sub-lattice of $\mathcal{L}$ and $\mathrm{m}^{\prime}=\mathrm{m}$.

The passage to a possible stochastic process representation that is distinctly on beyond the $\sigma$-field-real-valued-measure form now emerges in the following considerations. The representation of collections of eventualities by certain collections of c.l.m.'s in a unitary space holds forth the suggestion that, bearing on the stochastic processes in question, all the c.l.m.'s in the unitary space-among other structures as well, possibly-represent eventualities. Allowing that this may be the case we may then contemplate any pair of systems, say $\left(\mathcal{L}^{\prime}, \mathfrak{m}^{\prime}\right)$ and $\left(\mathcal{L}^{\prime \prime}\right.$, $\left.\mathrm{m}^{\prime \prime}\right)$, of the type that we were led to as representing a stochastic process; that is $\mathcal{L}^{\prime}$ is the ordinary lattice of spectral manifolds of a spectral measure and $\mathfrak{m}^{\prime}$ is a 1 dimensional manifold, and similarly for $\mathcal{L}^{\prime \prime}$ and $\mathrm{m}^{\prime \prime}$. Now we find ourselves confronting a new situation: in general not all the c.l.m.'s in $\mathcal{L}^{\prime}$ will commute with all the c.l.m.'s in $\mathcal{L}^{\prime \prime}$. If there is indeed such failure of complete commutativity then clearly $\left(\mathcal{L}^{\prime}, \mathrm{m}^{\prime}\right)$ and $\left(\mathcal{L}^{\prime \prime}, \mathrm{m}^{\prime \prime}\right)$ cannot possibly represent marginal processes of a single inclusive process according to the notion of marginality in the preceding paragraph. We thus have a situation which would seem to threaten the structural "principle of marginality", i.e., that any two processes are marginals of a third inclusive process. If this principle can be preserved there will at least have to be involved an enlargement of the representation of stochastic processes. We see that this is so because an inclusive process encompassing two processes with representations $\left(\mathcal{L}^{\prime}, \mathrm{m}^{\prime}\right)$ and $\left(\mathcal{L}^{\prime \prime}, \mathrm{m}^{\prime \prime}\right)$ as above, wherein not every c.l.m. in $\mathcal{L}^{\prime}$ commutes with every c.l.m. in $\mathcal{L}^{\prime \prime}$, will on this account have in its representation of eventualities paris of c.l.m.'s that do not commute. And this means that we are no longer within the mode of representation $(\mathcal{L}, \mathrm{m})$ where $\mathcal{L}$ consists only of the spectral manifolds of a spectral measure.

The simplest systematic way to probe after on enlargement of the representation of stochastic processes is to find, if possible, a type of lattice of configuration in a unitary space which lattice-type is no bigger than it has to be to do the job of achieving four things: (i) its general type of element should include c.l.m.'s; (ii) its g.l.b. and l.u.b. operations should coincide with the ordinary operations (i.e., intersection and c.l.m.-spanned-by) in the case of countable (or perhaps only finite) collections of commutative c.l.m.'s; (iii) it must admit inclusion of non-commutative c.l.m.'s (which is to say that the g.l.b. and l.u.b. operations must be defined for noncommutative c.l.m.'s); and (iv) it should comply with any other intuitive requirements that may be strongly or reasonably indicated by the representational structures we have discussed up to this point. Thus we come to a prescription of some definiteness.

Let us pause here to reflect on the substance of the suggestion we have made. 
We have proposed to go beyond the $\sigma$-field-real-valued-measure formalism by proceeding from the unitary space representation of that formalism and taking the step of allowing all c.l.m.'s in the unitary space into interpretation as eventualities. That step has destroyed the competence of the old mathematical notion of marginality and posed the mathematical problem of searching for a new marginality notion. Now, we have presented all of these deliberations in a purely mathematical light, pretending to rely on the mathematician's method of reasonable and interesting-appearing generalization. From this point of view it is then incumbent upon us to offer some empirical justification for our proposal. There is indeed such a justification. But it is really much more than a justification. It is, more correctly, a fact of knowledge of the real world that we were obliged to confront at some time and take fully into account in our theorizing if there is any validity to our unviersal statement that all real phenomena are stochastic processes. What we have reference to is, of coruse, quantum mechanics. There one encounters precisely the kind of situation we have talked about above: pairs of systems $\left(\mathcal{L}^{\prime}\right.$, $\left.\mathrm{m}^{\prime}\right)$ and $\left(\mathcal{L}^{\prime \prime}, \mathrm{m}^{\prime \prime}\right)$ wherein, although indeed $\mathrm{m}^{\prime \prime}=\mathrm{m}^{\prime}$, it is however not true that all the c.l.m.'s in $\mathcal{L}^{\prime \prime}$ commute with all those in $\mathcal{L}^{\prime}$. For exmaple, the c.l.m.'s in $\mathcal{L}^{\prime}$ might represent the eventualities of displacement of a particle and those in $\mathcal{L}$ " the eventualities of magnitude of momentum of the particle.

Our research at the present time is devoted to discovering a lattice, or lattices, which have the four qualities laid out above. The articles [8], [9], [10] and [11] are concerned with this. Before going on to describe very briefly this mathematical work let us say a little more about the condition (iv) above, which is quite vague in its stated form. An example of the intended implciation of this condition is seen when we consider the rôle of the 1-dimensional c.l.m., $m$, of the kind of system $(\mathcal{L}, \mathrm{m})$ discussed above, in producing the probabilities associated with the c.l.m.'s in $\mathcal{L}$. We launched ourselves into the present line of investigation by proposing. to accept the idea that all the c.l.m.'s in 5 represent eventualities. Consistent with this the c.l.m. $m$, too, is to be so understood. In this circumstance, if $\mathfrak{M}$ is a c.l.m. in $\mathcal{L}$, the probability determined for $\mathfrak{M}$ by $m$ appears as a number associated with an ordered pair of eventualities, and as such it is strongly reminiscent of a conditional probability in the traditional calculus of probabilities. Of course, we are far from having here a function on ordered pairs of eventualities with the same formal properties as conditional probability. Nevertheless, there is a quality of conditional probabilities that is readily generalizable to the present more complicated context and which suggests itself as a property that is to be preserved. We have in mind the fact that if the conditional probability of one eventuality relative to another is positive then these two eventualities, represented as sets, have a non-null intersection. In the context of the search for a new lattice that we are proposing, this property would be 
expressed by the following condition (where $\not$ means "not orthogonal to", and $\Rightarrow$ denotes logical implication, and $\wedge$ designates the lattice g.l.b. operation):

$$
\mathfrak{m} \chi \mathfrak{M} \Rightarrow \mathfrak{m} \wedge \mathfrak{M} \neq\{0\} .
$$

It will be noticed that the ordinary lattice of c.l.m.'s does not have this property.

In the article [8] we have presented the basis for the discovery of new lattices among which we may hopefully find one or more that exhibit the four properties we have been discussing. This basis is the mathematical notion of the flanking of a projection (or c.l.m.) by two given projections (or c.l.m.'s). In [8] we have built upon the notion of flanking the notion of a bicone, this being a certain kind of collection of projections. And we have shown that the bicones form a lattice, which we have called $\checkmark_{0}$ The articles [9] and [10] pursue further the properties of flanking; and [11] studies more deeply the pairwise spectral analysis of two projections, the analytical development on which the notion of flanking rests. - The lattice $\mho_{0}$ has the first three of the four qualities that have been set forth above, but it is suspected that it does not in general have the property (3.3.). We are therefore now investigating a modified flanking notion which we call enflanking, and it is anticipated that this will give rise to a new lattice; such a lattice will certainly possess the property (3.3.).

There is a very special aspect of the system $(\mathcal{L}, \mathfrak{m})$ of the type that has been figuring in our discussion. We saw the adjunction of $m$ to $\mathcal{L}$ initially as merely a mathematical device for expressing the probabilities associated with the system. Now, after we have come to look upon $m$ as of equal status with the elements of $\mathcal{L}$ in representing eventualities, this fact that the probabilities are generated by $\mathcal{L}$ and $m$ takes on a much more profound meaning: it says that the probabilities are already there implicitly contained in the eventualities. This is what underlies our suggestion, in Section I, that eventualities and acts alone are the fundamental stuff of which stochastic processes are made up. Probabilities are not independently fundamental: they are merely certain implicit relationships between eventualities.

If we bring this new insight to bear on our discussion, in Section II, of a dynamical law in a theory, we see that the properly formulated dynamical law in our theory will be expressed exclusively in terms of eventualities and acts. Our work is not yet at a stage where we can present the dynamical law and give substantiation of that presentation. However, intuition always runs recklessly ahead, and so we have given a suggestion in the article [8] of what the dynamical law might look like. We shall state it here. But this statement is not to be taken as a pronouncement; rather, it is to be considered at present only for its intuitive and heuristic content. The statement is as follows, where $\wedge$ and $\vee$ denote the lattice operations of g.l.b. and l.u.b., respectively, and $\ll$ designates the lattice order: 
For any collection of eventualities, $\left\{\Gamma_{\sigma}\right\}$ :

i) if $\Gamma_{\varpi_{1}} \ll \Gamma_{\varpi_{2}}$ and $\Gamma_{\varpi_{1}}$, actualizes, then $\Gamma_{\varpi_{2}}$ actualizes;

ii) if every $\Gamma_{\varpi}$ actualizes, then $\wedge_{\varpi} \Gamma_{\varpi}$ actualizes;

iii) if $\underset{\varpi}{\vee} \Gamma_{\varpi}$ actualizes, then some (one or more) $\Gamma_{\varpi}$ actualizes.

\section{IV.}

In the opening paragraphs of Section II we stated the remarkable foundational implications of the theory we are endeavoring to build. We saw, namely, that real structure is no longer to be seen as ultimately in terms of a space-time framework and matter-energy presences within that framework. Instead, it is eventualities and acts and probabilities which come forward as being at the fundamental level of description of reality. But we are now, after our discussion in Section III, prepared to drop even probabilities from this assertion, and thus to say simply that it is eventualities and acts alone that are the fundamental building-blocks of reality. Eventualities and acts are the substantive, objective, elementary pieces of reality, of which all phenomena, all systems, all things, all beings, are made up.

We wish to devote this present section to discussing some of the meaning of this affirmation in relation to human behavior.

A human being-each particular human being-consists of eventualities and acts. In grasping the significance of this we must be constantly alert to the distortive intrusions of our habitual ways of thinking. It is not that physically constituted Mr. Molnar standing there across the street, occupying that particular volume of space, that we are "alternatively" describing in terms of eventualities and acts. No. Our seeing Mr. Molnar on this occasion is but one of the acts that go to make up the reality surrounding and including Mr. Molnar as it is truly constituted. There are many acts that enter into the being of Mr. Molnar; for example: "that he cut his face while shaving this morning", "that his cat woke him up on Wednesday morning last week by nuzzling his neck", "that Miss Ferenc spoke to him on the telephone yesterday afternoon," "that last month he took his car to the mechanic to have the brakes fixed", "that he met yesterday in conference with his business associates", etc., etc. And there are the eventualities: "that the conference with his business associates would not take place yesterday", "that he will eat two apples tomorrow", "that he will take Miss Ferenc to dinner next Monday evening", "that he will discover a hole in his right sock when he takes his shoes off this evening", etc., etc. All of these eventualities and acts are also part of the make-up of other things and other human beings. It is clearly not a simple matter-at this stage in the development of these ideas, at any rate-to draw the boundaries which exactly define Mr. Molnar; that is, to characterize exactly which acts and eventualities are those that enter into the definition of Mr. Molnar, and 
which are those that do not. But in any case it is quite clear that Mr. Molnar is not, in his true definition, something apart from his razor, his cat, Miss Ferenc, his telephone, his car, his mechanic, his socks, etc., etc. In the classical scientific conception Mr. Molnar and all these entities are considered separate in their definition because they are physically isolable from each other in space. But in our conception this physical isolability is merely an aspect of certain marginal processes of these entities; that is, for example, the joint process that is $\mathrm{Mr}$. Molnar and his telphone has a marginal process that may be called the physical sub-process of the Mr. Molnar-his telephone process, and it is a property within this subprocess that the spatial extensions of Mr. Molnar and his telephone neither overlap nor are contiguous constantly in time. The act, "that Mr. Molnar spoke on his telephone yesterday afternoon", belongs to this physical sub-process. But if last Saturday evening Mr. Molnar cursed his telephone for having been out of order that day, then we have there an act that belongs to the joint Mr. Molnar-his telephone process but does not belong to the physical subprocess of that process. Thus, there is more to the joint being of Mr. Molnar and his telephone than just what attends the condition of their mutual physical isolability. And this more is part of what is Mr. Molnar and part of what is his telephone. Just so, Mr. Molnar shares his being beyond physical separateness also with his car, his business associates, Miss Ferenc, his shoes, etc., etc.

Let us observe now that if Mr. Molnar poses such questions as, "Who am I ?", "What am I?", "Where do I fit into the scheme of things?"-if he questions thus, he is asking for an indication of the nature of his identity as an entity in the real world, and the question deserves as penetrating an answer as it is possible to give in the light of the understanding of things. Thus, in our view, the only proper answer to Mr. Molnar is that he is a stochastic process, a structured agglomeration of eventualities and acts. We could, as we have done above, cite many examples of these eventualities and acts that make him up, but we can by no means list or characterize them all. That seems to be simply beyond us (as human beings, or perhaps in a more absolute sense). But most significantly we have, with this answer, given him a correct structural picture of himself. And the importance of this is that if he contemplates making an effort to "change himself", to alter his behavior-for whatever reason-then he will know correctly what are the basic elements with which he must deal, and so be able to be effective. This point can be illustrated by an analogy: if, on the basis of the readily available evidence, we theorize concerning a certain piece of painted statuary that it is made of wood, then if we desire to repaint a portion of it we may decide to first remove the old paint with the use of a blow-torch; if the statue was actually made of wax, then through our false understanding of the structure of it we should thus have dealt very harshly with it, the heat of the torch melting parts of it and damaging it 
perhaps quite badly. Or, another analogy: we might have a relatively large piece of material that we wished to cut into smaller pieces (for some commerical or artistic purpose, for example), and we might have no awareness of the distinction between amorphousness and crystallinity of physical structure, and consequently not be aware of the implications of the fact that our material is actually a crystalline substance (such as a diamond); we would proceed to cut the large piece along some arbitrarily chosen planes and soon find, to our dismay, that we were coming up with an inordinate number of shattered sections; with what remained of the large peice we might choose some random re-orientation and try again, and again find the same results; and the same kind of disappointing outcome might meet also our efforts at further cutting the first-cut sections, and so on; thus, while having at first envisaged the neat reduction of the initial mass of material to a large collection of exact, small cubes, we would actually have ended up with a a few cubes having exceedingly nicked edges and faces, and all the rest badly crumbled fragments; and so again, by reason of our not having understood the structural make-up of what we were dealing with (-crystalline spatial structure with definite planes of cleavage-) our efforts continued to produce only the most damaging results.

Having told Mr. Molnar-or Mr. Smith, or Mr. Svensen, or Mr. Tanaka-what is the nature and the substance of his identity, let us go on to examine what is implied for the question of greater or less identity.

Since a stochastic process consists of eventualities and acts it is immediately evident that a process is of greater substance the more eventualities and acts there are in it, in some sense. The phrase "in some sense" is crucial here because a stochastic process has a great deal of (mathematical) structure to it and therefore, it not being just a set of indifferent things, the cardinal number of its elements is not the unique comparative measure of its magnitude, or even necessarily a correct one for a particular concept of "magnitude". Indeed, it would seem that cardinality is irrelevant to the concept of identity. What appears to be the critical consideration here is-naturally enough-marginality. Let us keep in mind that we are seeking here to render a young, still-vague, literal concept into precise characterization in terms of the elements of a proposed exact theory, insofar as possibile-that is, insofar as the elaboration of that theory to date permits. It seems to us that that elaboration to date, even though not yet at the stage of fully detailed foundationing, does admit a precisement of the concept in question. (Or, we could say: the tentative explanation of "degree of identity" that we are about to give in terms of the precision elements of the theory that is being proposed would seem to speak strongly for the ultimate successful establishment of that theory.) We find that we are able to achieve a satisfactorily complete understanding of the idea of "degree of identity" without going beyond the analytical notion of margin- 
ality, and therefore other analytical notions, such as cardinality, are without direct pertinence.

A critical observation to begin with is that intuitive statements relating to degree of identity are of two kinds: there are those that refer to one real system being less than another real system, and those that refer to a given real system not being as much as it could be. In the first category are, for example, all the unconditioned assertions we hear from time to time to the effect that man is the "highest form" of animal life. Expressing the same idea are such spuriously analytical statements as that man is the only animal having a soul. Often we meet the idea expressed in more emotionally charged situations: "I am not a dog, to be treated thus," or "I am not just. a machine; my feelings count, too." Statements in the second category are frequently couched in terms of selfrealization: "the individuals of this or that group in such and such a society have been denied the opportunity for self-realization". In this second category are such comments as: "they are striving after the full expression of their selfhood;" "he does not feel he is being permitted to realzie his full potential as a human being"; "his own blocks are standing in the way of his full development"; "your cat won't really be able to be himself if you have him declawed"; "his house is not a home."

A statement like "man is the highest form of animal life" is widely questioned today. Expressions in spoken language are rather tending more and more to reflect a disenchantment with the old habitual readiness to enunciate comparative judgments regarding different qualities and attributes. For example, to support the "highest form" assertion about a human being one must argue that the ability of many clawed animals to climb a tree unaided is inferior to some other ability of a man, since a man does not have that tree-climbing ability; such orderings are arbitrary and at best ad hoc. Usage of the term "identity" today sees it as in the identity of certain animals that they are the exceptional climbers they are, while the identity of a man is otherwise, exceeding these animals in other respects but falling short of them in this quality. What we are getting at is this: the use of the term "identity" does not demand that its rigorization admit a universal comparability of identities. A definition of degree of identity does not have to provide a comparison between very two systems saying one is more or less than, or equivalent to, the other. On the contrary, just the reverse, rather, is what is expected of a reasonable definition. It seems to us, then, that one notion of "degree of identity" is captured in the following definition, which refers to the lattices of eventualities that make up (together with the pertaining acts) systems: Of two systems one will be said to have a lesser self than the other if the lattice of eventualities of the first is isomorphic to a sub-lattice of the lattice of eventualities of the second, but not isomorphic to that lattice itself.

Now, it would appear, quite possibly, to be the case that for each human being 
there is a certain marginal process of the process that is this human being, which marginal process-let us call it the kernel process of this human being-is the process that characterizes him as of the human species; and thus the kernel processes (or rather, their lattices of eventualities) for human beings are all mutually isomorphic. (We may, of course, be venturing to conceive too great an exactness here. Membership in a species may rather be a matter of a kernel process belonging to a class of processes which differ in their mathematical structure only very little (in some precise sense) one from another.) The birth of an extreme monstrosity might then provide an example of a process whose eventuality lattice is isomorphic to only a sub-lattice of the human kernel lattice, and hence an example of a system that has a lesser self than a human being. (The usual unfortunate cases of birth defects are not examples in point; they serve to inform us rather as to the nature of the kernel process of human beings.)

The fact of the kernel process seems indisputable. The ready evidence of actual individual differences among human beings suggests strongly that the full eventuality lattices of no two human beings are comparable.

A more immediate example of lesser self might be provided by two automobiles of the same make and series, the first of which lacks certain features that the other has; for example, sun visors, arm rests, etc. And a still more exact example is afforded by the two processes the first of which is a particular man and the second of which is the joint process of that man and his automobile.

This first notion of comparative identity that we have just defined presents itself more sharply if we explicitly define the self of a process to be the lattice of eventualities of that process. We do not wish to be considered as making, at this stage, any ultimate definitions of such familiar terms as "the self"; but this definition will serve our present discussion quite well. The self, then, as we have defined it, is not the entirety of a process: there are the acts also. Let us be explicit about another useful definition, which we have, in fact, already effectively made: the eventualities and acts of a process, together-thus, all that there is to the process-will be called the identity of the process. The self is therefore only a part of the identity of a process, or a system, and one of the ways in which one system may have a lesser identity than another system is for it to have a lesser self than the second system; and to this we have given an exact meaning in the definition above. The notion of "lesser self" characterizes one of the kinds of contrast that explain differential statements regarding two systems. There is also another kind; but first let us consider the statements of the second category that we have exhibited above, which make differential observations regarding the identity of one and the same system. In this case there is only one, fixed eventuality lattice, or self, involved, and therefore an explanation must have to do with the acts of the system.

What we are about to explicate is precisely the concept of self-realization. The 
self of a process may be more or less "realized" in the acts of the process. It is this variability that accounts for the meaningfulness of the statements above of the second category. To get at the idea that is concerned here let us look at the example of a certain smoker's pipe which, in addition, has a very artfully carved exterior, so that it is a collector's item as well as a device for smoking. The eventuality lattice of the process which is this pipe will have in it eventualities of lighting up and smoking and also eventualities of appearing on display. The process has, in fact, a marginal process which is the pipe's smoking process, and another marginal process which is the pipe's display process. Alternatively expressed: there is the sub-lattice of smoking eventualities of the pipe, and the sublattice of display enventualities of the pipe. Now, on the other hand, there is also the process which is the gentleman smoker and pipe fancier who, let us imagine, has just purchased the pipe we are speaking of at his tobacconist's shop and is on his way home with it in his briefcase. The pipe's self-that is, its lattice of eventualities-does not contain the eventualities of decision by the gentleman to smoke or display the pipe and the eventualities of his taking the necessary preparatory steps for such actions. These eventualities are contained in the larger self of the joint pipe-gentleman process. Thus, it begins to emerge that the evolution of a process, in this case the pipe, will in general depend on the evolution of the more comprehensive process which is the pipe plus its environment. The gentleman may start out by smoking the pipe for a week or two and during that time develop strong feelings one way or the other with regard to it. It may provide him with such a tasty smoke that he will simply go on smoking it regularly as he would any other pipe, and perhaps only on occasion relinquish it for display in an exposition of objects of art. Or, during that initial period of smoking the pipe he may be taken more and more with its beauty and experience a growing reluctance to use it for smoking; and he may then set it on a stand in some prominent place in his home and proceed not to smoke it again. In the latter case, for example, we have an instance of the failure of full self-realization of the pipe: the evolution of its smoking sub-process is cut off; there persists a failure of the pipe's smoking eventualities to actualize.

The lack of self-realization in a process that is a human being is of the same nature: there are sub-processes of that human being in which actualization is thwarted. It may be, for exmaple, a promising young athlete who meets with an accident one day in which his leg is broken and he is thereafter not able to run again. Or it may be a person whose conditions of residence, training, etc., prevent him from earning a sufficient income to enable him to travel about and move in other places and other cultures. Or, as another example: a man who is unable to make and keep friends as a result of his early behavior pattern formations.

Whether it be in the case of a human being or a smoker's pipe or any other 
system, limited evolution of the various sub-processes of the system is a form of diminution of identity of the system: there is not the wealth and variety of acts that there might otherwise be in the identity of the systein. The pipe is more fulfilled if it is smoked as well as set out for exhibit; the human being is more fulfilled if he does travel and if he does have friends. In this concept of lack of "realization" (or, more correctly, lack of full actualization) of the self we have, thus, a second notion of comparative identity. The first notion, that of lesser self, was associated only with eventualities; this second one, by contrast, concentrates on the acts.

We said earlier that there is another kind of comparative identity that is pertinent in the case of two systems. We can now mention it; it is a combination of the first two. That is, two systems may have isomorphic selves but one may enjoy less self-realization than the other. For example, the kernel processes of two human beings, one of whom lives a productive life in warm association with many individuals, and the other of whom lives as a sullen hermit. Or two dice, one of which finds its way to the gaming tables of Monaco and the other of which is lost in transit from the factory and lies rotting in the city dump.

We have now presented what would appear to be the three natural modes of contrast of identities. They are natural in that they refer only to the basic constituent elements of stochastic processes and entail no contrived measures or arbitrary judgements. And they appear to explain effectively all the empirical evidence around today which is understood at the purely intutitive level as having to do with identity. For example, let us return to our discussion in Section II where we saw that the reachings for self-fulfillment in the world today defy explanation in traditional terms. People are seeking and (when they are not thwarted) finding greater fulfillment by modes of behavior that are definitely not in the line of traditional prescription for greater identity-which is to say, they are not engaged in fattening their purses or amassing physical possessions or pursuing longevity for its own sake. Then what is it that they are doing in the pursuits we alluded to in Section II that does bring the sense of fulfillment? The answer is: they are pressing more and more of their marginal processes into actualization. This is precisely the rigorous description of the activities we are witnessing on the part of the brave new individuals-such activities as participating in programs of social betterment at home and abroad, venturing new group-living arrangments, growing beards, attending mass music festivals, participating in encounter groups and other awareness-awakening situations, etc., etc. The broadest gains in selfrealization for a human being, though by no means all the major ones, seem to be associated with joint processes involving other human beings; that is, it is the evolution of such joint processes in particular that is significant for the opening up or the closing off of actualization in a principal array of subprocesses of the given 
human being (-just as it was, in our earlier discussion, the evolution of the joint pipe-gentleman process that was significant for the opening up or the closing off of the pipe's smoking sub-process). (Accounting for this seeming emperical fact may be some very specific aspect of structure of the stochastic processes in question; this will come to light when the mathematical developments have gone far enough.) Thus we find the main body of emergent activity of one of these new individuals we are talking about to be concerned with other human beings. Let us stress this point: the search for greater identity, or self-realization, is most largely answered through increasing relationships with other human beings.

We characterized in Section II also the class of individuals who freely pursue the goal of increased physico-temporal extension and who find that it does not bring self-realization. The fact is that such behavior is actualization in only a very restricted part of the self, a very restricted sub-process of the individual. Thus, it is distinctly not behavior which is opening up actualization in more and more sub-processes. There is the vicious deception that greater economic wealth provides greater self-realization. But there is no such thing as economic substitutability of stochastic processes. It is not true that every stochastic process has its price! The joint process of two human beings is in no way equivalent to the joint process of the first human being and his wealth. Their eventualities are altogether different; their evolutions cannot be mistaken one for the other.

Finally, we mentioned in Section II the case of persons who live under conditions of equidistribution of material wealth and who also find themselves lacking personal fulfillment. Again here the point is that no environmental influencing of the economic subprocesses of individuals has any automatic substitutability for the evolution of other sub-processes of these individuals. If there is stoppage of these other sub-processes then there is lack of self-realization.

We have drawn on some very large-scale social phenomena to point up the validity of our conception as against the fallacy of the classical scientific conception. There is another good illustration of this contrast. The University of California has, centered on its Berkeley campus, a program of activity conducted by a committeee known as the Special Committee for Development of Communication with Negro Colleges and Universities (SCDCNCU). The ultimate aim of this program is to help build the currently predominantly Negro institutions of higher learning into first-rate educational centers where this is not already the case. But the actual defining concept of the program is that it will direct its efforts to creating close, personal, on-going relationships between individual teachers and scholars on the Negro college campuses and their counterparts at other institutions. The program has been operating for five years now, as of the date of this writing, and its growth is still accelerating. (The scope of the program is universal; it is by no means restricted to the University of California.) We shall not here describe the many 
large and small educational enhancements that have accrued to the institutions, both predominantly Negro and predominantly white, whose faculty members have become involved (-there are annual reports, freely available, which describe these results). But the total of these gains, together with the unsolicited evaluative comments that are constantly offered, suggests that this program is proving, on the whole, more successful than programs of other types (for example, the "big sister" type, in which a major university associates itself with a single Negro college in an arrangement drawn up at the top administrative level.) Why is this so? The answer is that very many more marginal processes are opened into actualization by the SCDCNCU program than by other programs: there is much more identity, much more self-realization generated. And the enhancement of an educational process (the joint stochastic process of a school, its faculty and its students) is one and the same thing as the fuller self-realization of this process. In a formalized cooperative arrangement between two schools there might, for instance, be a decision made to enter into the process of building up the instructional program in, say, mathematics at the smaller school. This is a relatively restricted sub-process of the joint process of the two schools and their faculties and student bodies. It will, perhaps, involve such acts as the appointment of committees to study needs and recommend action, solicitation and/or designation of faculty members to participate, visits by faculty from the smaller school to lecture and study at the larger school, visits by faculty of the larger school to lecture at the smaller school. Just how restricted this process can be is seen by looking at some of its more intimate eventualities and acts and availing oneself of empirically known facts about the dynamics of such processes. For example, faculty members already very busy with teaching, research and other duties may seriously resent additional obligations to serve on a committee and therefore give much less than their most creative best to the work of the committee. Visitors from the smaller campus to the larger may find themselves in an environment of preoccupied, overly busy people who can provide their guests with no after-hours softness to break the rigor, so that over an extended period of time the job of teaching and absorbing becomes an onerous one; what can be learned under such cricumstances, for eventual carrying away and application elsewhere, is limited in many ways. Such effects as these make for a very narrowly developed cooperative mathematical instruction process. The behavior fits tight around the least understanding of the expression "cooperation in mathematical instruction programs", and myriad other eventualities are not actualzied. For example, many novel ideas might fail to come to light because of the lack of personal interest in the project; innovations made at the smaller school might die for lack of sustained attention; resulting strained feelings on the part of faculty members of the smaller school might result in their not recommending that particular large school to their 
students for graduate study; opportunities for supportive grants might be lost for want of spontaneous cooperative efforts by the individuals concerned to seek them out; the failure of development of any significant social ties between individuals of the two faculites might result in the loss of many new productive personal contacts; etc., etc. Motivated to promulgate evidence of the success of their cooperative arrangement, the two schools, as administrative entities, might cite the numbers of faculty who have visited between the campuses, the number and variety of courses given, and so forth. But these numbers, as we see from the list of items just preceding, do not measure the degree of self-realization of the cooperative mathematical-instructional process. Here again is the fallacy of the traditional conception of identity at work.

In contrast to this, the SCDCNCU program lays constant primary stress on the fullest possible development of individual personal relationships. And in fact this is its exclusive concern as a program. It operates to initiate and nurture close, on-going relationships between individuals and it leaves it to these relationships themselves to generate the activities that result in educational enhancements. For example, the program will bring together a psychologist on the faculty of a large, flourishing school and a psychologist on the faculty of a smaller school. But it will propose absolutely no plans of action to these two professors. It will sponsor visits by each of them to the other's campus where he will, at an unhurried pace, perhaps give one or more lectures, meet other professors and students on an informal basis, learn the nature of the school, come to know its problems and how they are handled, observe the instructional and research programs, get the feel of the school's environment, etc., etc. The program then stands ready always to support subsequent travel by these individual to assist them in the elaboration and execution of promising developmental plans that they may devise. In the same spirit the program will sometimes cause to be brought together in one place at one time several people who have a common developmental concern, in order that there may be a much broader exchange of ideas and formulation of plans. Thus, the program operates directly and intensively at precisely the task of opening up subprocesses to actualization. And in working at the interpersonal level in a sincere way (-that is, it pays heed to continuing nurture of individual relationships and and does not sacrifice this for an attempt at mass production of contacts-) it gets at vastly more of the sub-processes of the over-all joint educational process.

We wish now to say a few words on one last topic. The theory we are proposing to establish affirms a structure of reality that is radically different from what has traditionally been supposed to be correct. On standing back and looking at this contention, one may be inclined to put such questions as the following: How can that be right? How can we possibly be so far from the truth? Generations of scientists have followed one upon the other and always the space-time 
framework, and physical evidence within it, have been seen as entirely natural; how can the true state of affairs have escaped the attention of so many for so long? There is an answer to these questions, and it is found exactly where one would realistically look for it: in the growth process of the child. In fact, it seems that the critical stage can be pinned down rather closely. In his studies Jean Piaget finds that it is at the age of about 8 or 9 months that there first appear patterns of behavior that can be properly called intelligent. It is here that the child begins to employ intentionally various "schemata" in new combinations to achieve distinguished ends: "....L'acte intelligent est ainsi constitute', qui ne se borne pas à reproduire sans plus les résultats intéressants, mais a atteindre ceux-ci grace à des combinaisons nouvelles." He goes on to say, concerning this stage of development: [12, p. 187] " $D u$ point de vue des catégories réelles, un tel progrès conduit, comme nous le verrons au cours du volume $I I$, à une conséquence essentielle: en coordonnant les schèmes qui constituent les instruments de son intelligence, l'enfant apprend ipso facto à mettre en relation les choses elles-mêmes entre elles. En effet, les rapports concrets unissant les uns aux autres les objets du monde extérieur se construisent en même temps que les relations formelles des schèmes entre eux, puisque ceux-ci représentent les actions susceptibles de s'exercer sur les objects. Le parallélisme de ces deux séries, réelle et formelle, est même si étroit que, au cours des premiers stades, il est bien diffcile de dissocier l'un de l'autre action propre et object. Au fur et à mesure, au contraire, que l'action se complique par coordination des schèmes, l'univers s'objective et se détache du moi...."

In these last two sentences we have the account of the inevitable stumble, the inevitable self-deception. The child goes over from a sense of the process to the concept of physical definition of objects, the delusion of the physical thing-in-itself. The child is here being misled by his senses in the same natural pattern as were his forefathers. But these antecedents of his have long since fixated this erroneous conception, and now they reinforce the child's misconception. Everything in the society around him corroborates the child's mistake of abstractions for reality, this false build-up of insight that he has. In a future, more knowledgeable society it is precisely at this stage that the soceity will bring its utmost to bear to divert the child from thus veering off into an illusion. As things are now we indoctrinate him further and further into the illusion, where we ourselves stand.

It is not unreasonable to conjecture that on this period in the child's life turns a major part of the emotional experience he will undergo throughout his lifetime. As the child grows more and more into the false framework of ideas he, along with the society, is tending accordingly to fashion his behavior in one way while in fact it is in the true nature of reality that his behavior would have to be fashioned altogether differently to achieve desired ends. Thus, for example, all of our discussion above concerning search for identity. Or, consider the extent to 
which the deception that physical separateness is separateness of being leads to the alienation of human beings from one another, of families from families, groups from groups, and nations from nations-to the point of indifference, hostility, and war. Yet, it is in the true nature of being that we, so to speak, exist in each other: by our on-going interactions the marginal processes of each of us are opened up and the self caused to blossom, to be to its fullest extent. It may very well be that the vast domain of emotion that we call love is nothing other than the operation of the structural truth about ourselves, in later life taking on more accentuated forms as it struggles for expression against the intellectual bonds with which we strapped ourselves at the age of nine months.

\section{References}

[1] Edward W. Barankin, Quantitative Theory of Human Behavior, RAND Corporation Research Memorandum RM-900, Santa Monica, February 8, 1952.

[2] Edward W. Barankin, "Toward an objectivistic theory of probability", Proceedings of the Third Berkeley Symposium on Mathematical Statistics and Probability, Vol. 5, University of Califronia Press, Berkeley, 1956, pp. 21-52.

[3] Edward W. Barankin, "Quelques remarques sur une théorie du comportement," Economie Appliquée, 1 (1957) 13-17.

[4] Edward W. Barankin, "Concerning the mind-body problem," Theories of the Mind (Ed., J. Scher) The Free Press of Glencoe, Macmillan Co., New York, 1962, pp. $582-597$.

[5] Edward W. Barankin, "Statistics and its place in science," Journal of the Institute for Research in Productivity, Waseda University, 8 (1964) 2-19 (in both English and Japanese).

[6] Edward W. Barankin, "Probability and the East", Annals of the Institute of Statistical Mathematics, Tokyo, 16(3) (The Twentieth Anniversary Volume, Part II) (1964) 185-230.

[7] Edward W. Barankin, "Probability and behavior and Eastern thought," Psychologia, VIII (1-2) (1965) 63-72.

[8] Edward W. Barankin, "Toward the mathematics of a general theory of behavior, I-the lattice $\Im_{0} ., "$ Annals of the Institute of Statistical Mathematics, Tokyo, 21(3) (1969) $421-456$.

[9] Edward W. Barankin, "Toward the mathematics of a general theory of behavior, II-a characterization of flanking", Annals of the Institute of Statistical Mathematics, Tokyo, 22(2) (1970) 187-202.

[10] Edward W. Barankin, "Toward the mathematics of a general theory of behavior, IIIthe flanking heredity theorem"; to appear.

[11] Edward W. Barankin, "Unitary equivalence in pairwise spectral analysis", Nagoya Mathematical Journal, Vol. 37 (special volume honoring the 60th birthday of Professor Katuzi Ono), March, 1970, 12-23. [12] Jean Piaget, La Naissance de l'Intelligence chez l'Enfant, Delachaux et Niestlé, Paris,
1948. 